Supporting Information

\title{
Synthesis of Bimetallic Au-Ag/CMK-3 Catalysts and Their Catalytic Activity for the Oxidation of Amino Alcohol
}

Xiangzhan Meng, ${ }^{\text {a,b }}$ Ruiyi Yan, ${ }^{b}$ Shouwei Zuo, ${ }^{\text {d }}$ Yongqiang Zhang, ${ }^{\text {a,b }}$ Zengxi Li ${ }^{\text {a, }}$, and Hui Wang ${ }^{\text {b,c,* }}$

${ }^{a}$ School of Chemical Sciences, University of Chinese Academy of Sciences, Beijing 100049, P.R. China

${ }^{\mathrm{b}}$ Beijing Key Laboratory of Ionic Liquids Clean Process, CAS Key Laboratory of Green Process and Engineering, State Key Laboratory of Multiphase Complex Systems, Institute of Process Engineering, Chinese Academy of Sciences, Beijing 100190, P.R. China

${ }^{\mathrm{c}}$ Innovation Academy for Green Manufacture, Chinese Academy of Sciences, Beijing 100190, P.R. China

${ }^{\mathrm{d}}$ Beijing Synchrotron Radiation Facility, Institute of High Energy Physics, Chinese Academy of Sciences, Beijing 100049, P. R. China

*Corresponding authors: lizengxi@ucas.ac.cn (Z. Li), huiwang@ipe.ac.cn (H. Wang) 


\section{Characterizations}

The specific surface area $\left(\mathrm{S}_{\mathrm{BET}}\right)$, pore volume, and average pore size were measured at $77 \mathrm{~K}$ from the $\mathrm{N}_{2}$ adsorption-desorption isotherm on a Micromeritics ASAP 2460 apparatus. The powder X-ray diffraction (XRD) patterns were recorded on a Rigaku RINT 2500 diffractometer using monochromated $\mathrm{Cu} \mathrm{K} \alpha$ radiation $(\lambda$ $=1.54060 \AA$ ) at $30 \mathrm{kV}$ and $15 \mathrm{~mA}$. X-ray photoelectron spectra (XPS) were recorded on a PHI-5400 spectrometer with an Al Ka source. The binding energy scale was calibrated relative to the $\mathrm{C} 1 \mathrm{~s}$ peak $(285.0 \mathrm{eV})$ of contaminant carbon. The transmission electron microscopy (TEM) images were collected using a JEOL JEM-2100F operated at $200 \mathrm{kV}$. Samples were deposited on the TEM grids after dispersion in ethanol. The atomically resolved high-angle annular dark field scanning transmission electron microscopy (HAADF-STEM) images were taken on a JEM-ARM300F instrument operated at $80 \mathrm{kV}$. The Au loading in the catalysts was determined by inductively coupled plasma optical emission spectroscopy (ICP-OES) using an IRIS Intrepid II XSP (Thermofisher, USA). The total Ag/Au ratio was obtained by Oxford Aztec energy dispersive X-ray spectroscopy (EDS) system.

X-ray absorption fine structure (XAFS) measurements for the $\mathrm{Au} \mathrm{L}_{3}$-edge were performed in the transmission and fluorescence modes at room temperature with the XAFS station of the 1W1B beamline of Beijing Synchrotron Radiation Facility (BSRF, Beijing, China). XAFS data were analyzed using IFEFFIT software package ${ }^{1}$. Temperature-programmed desorption of hydrogen $\left(\mathrm{H}_{2}\right.$-TPD) experiments were performed on a Micromeritics Autochem 2920 (Micromeritics, USA) equipped with a TILON LC-D200 mass spectroscopy system in real-time as the detector. The loading of each sample was $126 \pm 2 \mathrm{mg}$ and the catalysts were treated in the reactor in a gas mixture of $\mathrm{H}_{2}$ and $\mathrm{Ar}(1: 9, \mathrm{v} / \mathrm{v})$ at $323 \mathrm{~K}$ for $60 \mathrm{~min}$. Subsequently, Ar was flowed into the reactor at $323 \mathrm{~K}$ for $30 \mathrm{~min}$ to remove physisorbed and/or weakly bound species. After flushing with Ar until a stable baseline was obtained, the temperature was raised to $1073 \mathrm{~K}$ with a heating rate of $10 \mathrm{~K} \mathrm{~min}^{-1}$ and the $\mathrm{H}_{2}$ desorption profiles were measured online by fixing the $m / z$ signal at $2 .{ }^{1} \mathrm{H}$ NMR spectra were recorded on a 
Bruker AVANCE III HD NMR spectrometer operating at $600 \mathrm{MHz}$.

All the samples were characterized by the above methods after preparation without handling, unless otherwise noted. 
Textural properties of $10 \mathrm{Ag} 90 \mathrm{Au} / \mathrm{CMK}-3$ with different total metal loadings

Table S1. Textural properties of 10Ag90Au/CMK-3 with different total metal loadings.

\begin{tabular}{lccc}
\hline $\begin{array}{l}\text { Loading } \\
(\mathbf{w t} \%)\end{array}$ & $\begin{array}{c}\mathbf{S}_{\mathbf{B E T}} \\
\left(\mathbf{m}^{\mathbf{2}} \cdot \mathbf{g}^{-\mathbf{1}}\right)\end{array}$ & $\begin{array}{r}\text { Pore volume } \\
\left(\mathbf{c m}^{\mathbf{3}} \cdot \mathbf{g}^{-\mathbf{1}}\right)\end{array}$ & Pore diameter $(\mathbf{n m})$ \\
\hline 0 & 1190 & 1.41 & 5.16 \\
1 & 1156 & 1.40 & 5.19 \\
3 & 1064 & 1.31 & 5.21 \\
\hline
\end{tabular}


$\mathrm{H}_{2}$-TPD of 10Ag90Au/ $\mathrm{ZrO}_{2}$ and $\mathrm{ZrO}_{2}$

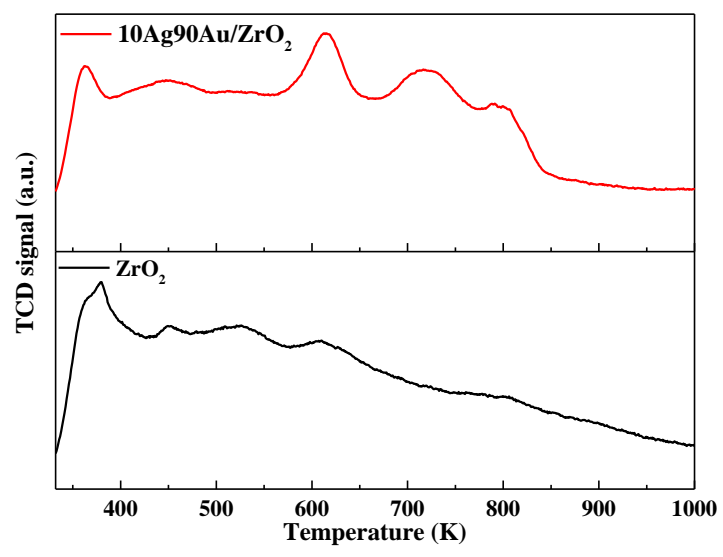

Figure S1. $\mathrm{H}_{2}$-TPD profiles of the prepared $10 \mathrm{Ag} 90 \mathrm{Au} / \mathrm{ZrO}$ catalyst and $\mathrm{ZrO}_{2}$ support. 


\section{$\mathrm{H}_{2}$-TPD of the prepared catalysts recorded by TCD detector}

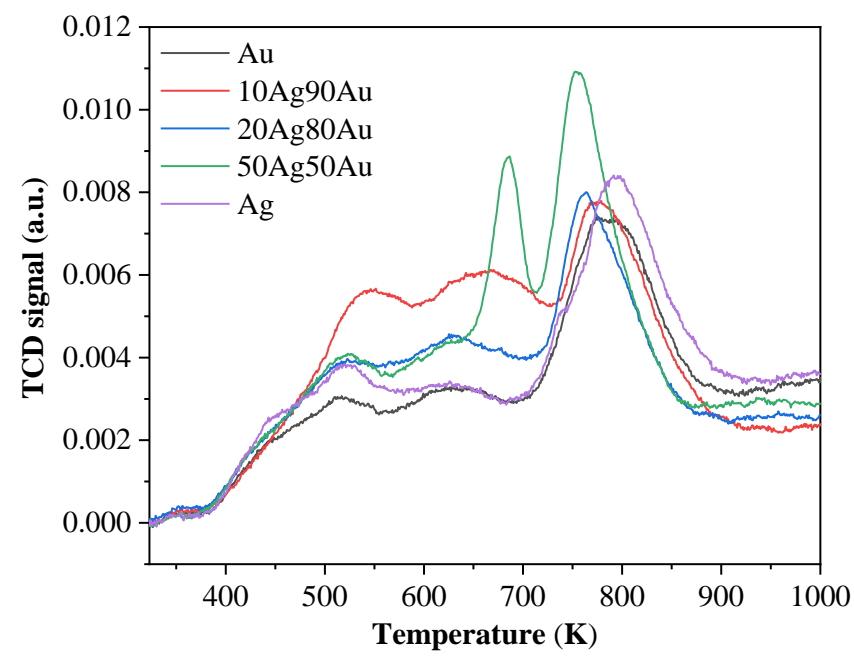

Figure S2. $\mathrm{H}_{2}$-TPD profiles of the prepared catalysts (the catalyst support sign was not included in the legends for simplicity).

Table S2. Comparison of integral peak areas of $\mathrm{H}_{2}$-TPD profiles shown in Figure $\mathrm{S} 2$ and the calculated results of desorption amount of $\mathrm{H}_{2}$ based on $\mathrm{H}_{2}$-TPD-MS of the prepared catalysts shown in Table 2 (the catalyst support sign was not included in the legends for simplicity).

Catalysts Integral peak area

Desorption amount of $\mathrm{H}_{2}$ shown in Table $2(\mu \mathrm{mol} / \mathrm{g})$

\begin{tabular}{ccc}
\hline $\mathrm{Au} / \mathrm{CMK}-3$ & 0.97 & 0 \\
$10 \mathrm{Ag} 90 \mathrm{Au} / \mathrm{CMK}-3$ & 1.88 & 2.97 \\
$20 \mathrm{Ag} 80 \mathrm{Au} / \mathrm{CMK}-3$ & 1.36 & 2.61 \\
$50 \mathrm{Ag} 50 \mathrm{Au} / \mathrm{CMK}-3$ & 1.59 & 2.70 \\
$\mathrm{Ag} / \mathrm{CMK}-3$ & 1.14 & 0 \\
\hline
\end{tabular}


More HADDF-STEM images of 10Ag90Au/CMK-3

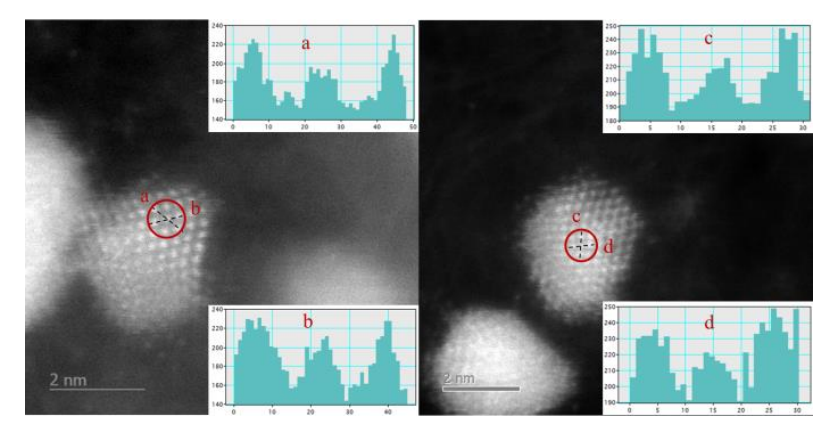

Figure S3. Typical HADDF-STEM images of Au-Ag alloy nanoparticles of 10Ag90Au/CMK-3 (surface isolated atomic sites on fcc (111) were marked with red cycles, and inserted graphs of a, b, $\mathrm{c}$, and d showed the integrated pixel intensity along the black lines of a, b, c, and d, respectively.) 


\section{Kinetic data}
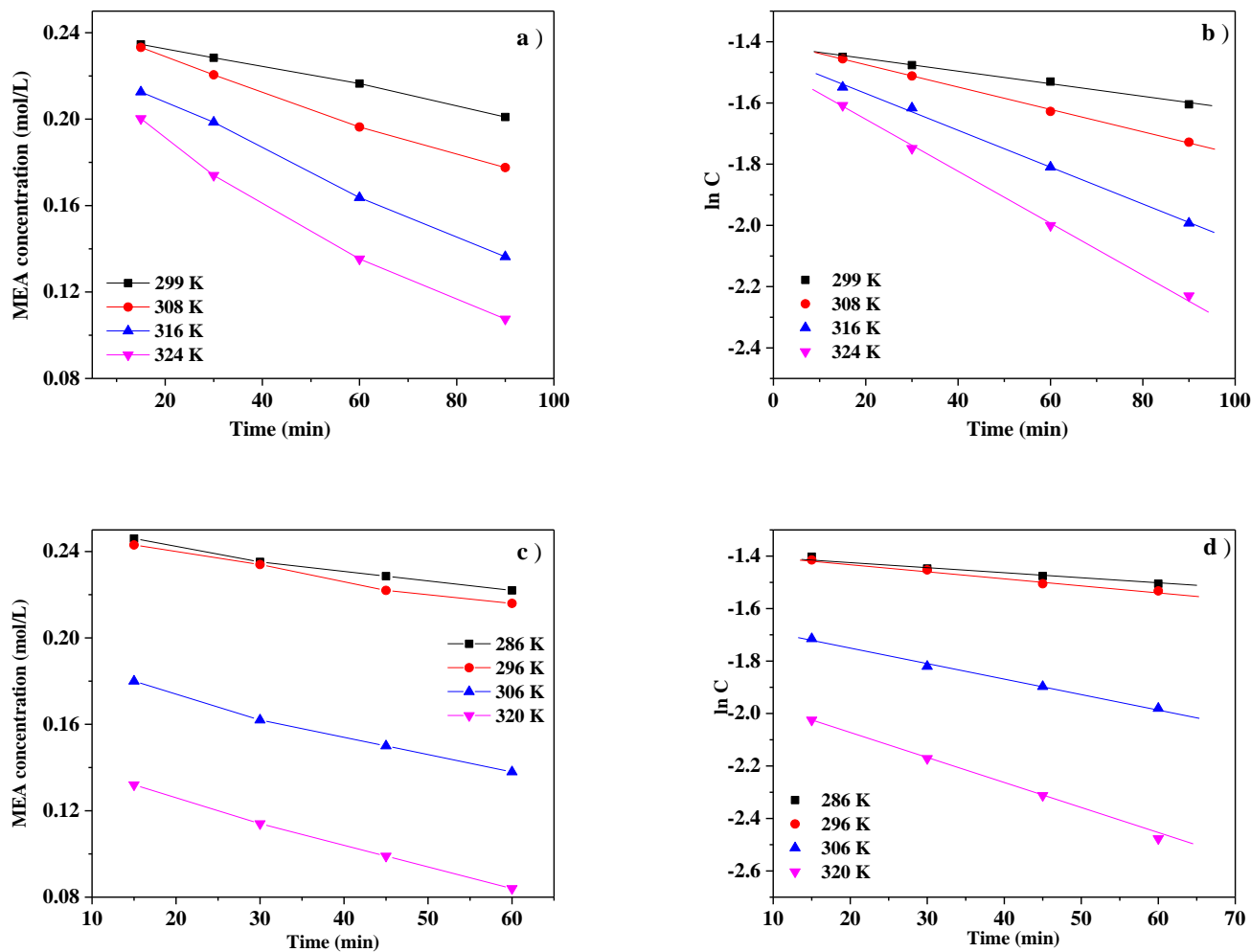

Figure S4. a) Change of $C_{\mathrm{MEA}}$ with reaction time at different temperatures over $\mathrm{Au} / \mathrm{CMK}-3$;

b) change of $\ln \left(C_{\mathrm{MEA}}\right)$ with reaction time at different temperatures over $\mathrm{Au} / \mathrm{CMK}-3$; c) change of $C_{\mathrm{MEA}}$ with reaction time at different temperatures over $\left.10 \mathrm{Ag} 90 \mathrm{Au} / \mathrm{CMK}-3 ; \mathrm{d}\right)$ change of $\ln \left(C_{\mathrm{MEA}}\right)$ with reaction time at different temperatures over 10Ag90Au/CMK-3.

Table S3. Linear regression results of the data in Figure S4 b) and d).

\begin{tabular}{cccc}
\hline Catalyst & Temperature (K) & Regressive equation & $\mathbf{R}^{2}$ \\
\hline Au/CMK-3 & 299 & $\mathrm{y}=-0.00204 \mathrm{x}-1.41576$ & 0.989 \\
& 308 & $\mathrm{y}=-0.00365 \mathrm{x}-1.40293$ & 0.998 \\
& 316 & $\mathrm{y}=-0.00602 \mathrm{x}-1.44827$ & 0.998 \\
& 324 & $\mathrm{y}=-0.00827 \mathrm{x}-1.49378$ & 0.980 \\
$\mathbf{1 0 A u 9 0 A u / C M K - 3}$ & 286 & $\mathrm{y}=-0.002 \mathrm{x}-1.38581$ & 0.980 \\
& 296 & $\mathrm{y}=-0.00342 \mathrm{x}-1.35066$ & 0.993 \\
& 306 & $\mathrm{y}=-0.00583 \mathrm{x}-1.63463$ & 0.999 \\
\hline
\end{tabular}




\section{References}

1. Newville, M., IFEFFIT: interactive XAFS analysis and FEFF fitting. J. synchrotron radiat. 2001, 8, (2), 322-324. 